\title{
Low markers of muscle damage and inflammation following a 3-day trail run
}

\author{
Emmerentia C Denissen (MTech Hom) \\ Anton H de Waard (MTechHom) \\ Navin R Singh (MSc (Eng)) \\ Edith M Peters (PhD) \\ Division of Human Physiology, School of Laboratory Medicine and Medical Sciences, College of Health Sciences, University of KwaZulu- \\ Natal, Westville, Durban, South Africa
}

Correspondence to: Edith Peters-Futre(futree@ukzn.ac.za)

\begin{abstract}
Objectives. To investigate the effect of a 3-day trail run on markers of muscle damage and inflammation in recreational runners. Main outcome measures. Pre-and post-stage and 24-hour and 72hour post-race concentrations of serum creatine phosphokinase (CPK), high sensitivity C-reactive Protein (hsCRP), cortisol, cardiac Troponin T (cTnT), and osmolality (sOsm) as well as urinary myoglobin (uMb), changes in body mass, delayed onset muscle soreness (DOMS) and thigh circumference (TC) were measured. Continuous recordings of heart rate (HR) and intestinal temperature $\left(\mathrm{T}_{\text {intest }}\right)$ were made throughout each stage.

Results. Heart rate ranged between $77 \%$ and $83 \%$ age-predicted maximum (APmax) and $\mathrm{T}_{\text {intest }}$ between 36.1 and $40.2^{\circ} \mathrm{C}$ during the three stages. Significant rises in mean serum CPK, hsCRP, sOsm and blood neutrophil count reached peak concentrations of $1488 \mathrm{U} / \mathrm{l}, 8.91 \mathrm{mg} / \mathrm{l}, 298 \mathrm{mosm} / \mathrm{l}$ and $10.2110^{9} / \mathrm{l}(\mathrm{p}<0.001)$, respectively. No evidence of elevations in $\mathrm{uMb}$ and $\mathrm{cTnT}$ were detected. The stage-induced increments in DOMS correlated positively with CPK, $\mathrm{r}=0.71 ; 95 \% \mathrm{CI}[0.62,0.78]$, TC decreased significantly post $S 1_{\text {post }}$ and $S 2_{\text {post }}(\mathrm{p}<0.05)$ and a maximum mean body mass loss of 3.09\% ( $\pm 1.04 \%)$ occurred during S2.

Conclusion. Three consecutive days of $95-\mathrm{km}$ trail running resulted in low markers of muscle damage and inflammation, despite the maintenance of a heart rate above $77 \%$ APmax, $\mathrm{T}_{\text {intest }}$ rising above $39^{\circ} \mathrm{C}$ and mean body mass decrement of $>2.0 \%$.
\end{abstract}

\section{Introduction}

Trail running events are becoming increasingly popular with amateur athletes. ${ }^{1}$ These are generally regarded as more strenuous than road running due to the nature of the trails, which can involve diverse challenges including single track paths on steep ascends and descends in mountains, crossing rivers and running along grasslands and through forests. ${ }^{2}$ Although physiological response to single-day trail running has been assessed, ${ }^{1-4}$ the cumulative effects of multi-day trail running on markers of muscle damage and inflammation have not yet been reported.

Prolonged endurance exercise causes muscle damage that initiates an inflammatory response and subsequent remodelling of muscle. ${ }^{5}$ The extent of this damage is augmented by increases in exercise intensity, the eccentric component of contraction, ${ }^{6-8}$ heat stress index and dehydration. ${ }^{3}$ The greater contractile load per unit in muscles of the lower limb, as they contract eccentrically during downhill running, ${ }^{8}$ has been associated with increased mechanical damage to the muscle fibres, resulting in muscle membrane leakage and elevated concentrations of circulating muscle enzymes and proteins. ${ }^{9}$ Systemic markers of inflammation also rise ${ }^{5,7}$ and swelling, decreased mobility and delayed-onset muscle soreness (DOMS) are common. ${ }^{5,6}$ The presence of myoglobin in the urine has been reported in severe cases.

Although the direct cause-and-effect relationship between dehydration and hyperthermia is currently contentious, ${ }^{10}$ it has been reported that these augment exercise-induced muscle damage, detrimentally affect performance and pacing during trail running and increase post-exercise DOMS. ${ }^{3,4,11}$ Cleary et al. ${ }^{11}$ reported an association between dehydration and hyperthermia and attributed an increase in muscle damage to the increased degradation of muscle proteins with elevated deep-muscle temperature.

The aims of the study were therefore to determine effects of a multiday trail run on the markers of muscle damage and inflammation in experienced recreational runners, measuring serum and urinary levels of selected skeletal muscle, cardiac and hepatic proteins in association with changes in red and white blood cell and serum cortisol concentrations before and after every stage and at 24 hours post-race (24PR) and 72 hours postrace (72PR). A further aim was to assess the possible effect of dehydration and hyperthermia on the markers of muscle damage and inflammation.

It was hypothesised that the three consecutive days of trail running would result in elevations of systemic and urinary markers of skeletal muscle damage and inflammation that are higher than previously reported during road running events of similar duration, and that the muscle damage and inflammation would be augmented by hyperthermia and dehydration.

\section{Method}

\section{Ethical clearance}

This 8-day observational cohort study took place during a 3-day trail run and for 5 days following completion of the Three Cranes Trail Run, at Karkloof, KwaZulu-Natal, South Africa on 25 - 27 February 2011.

Following approval by the Biomedical Research Ethics Committee of the University of KwaZulu-Natal, subjects gave written consent after having been informed of the experimental procedures.

\section{Subjects}

Twenty-one apparently healthy subjects, who met the inclusion criteria (age: $\leq 50$ and an average training distance of $60 \mathrm{~km}$ per week) 

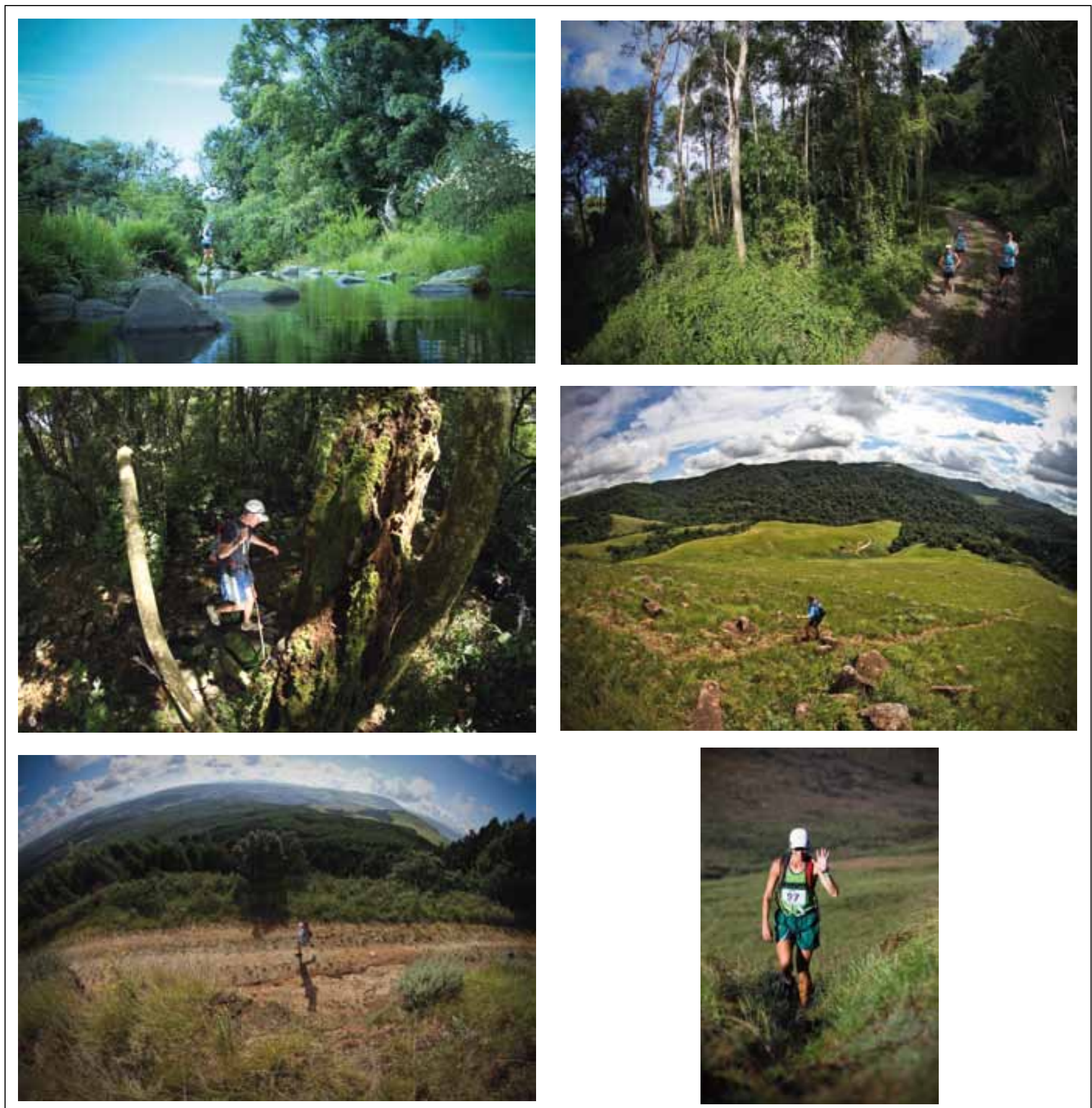

Fig. 1. Selected images of the running terrain.

and did not use chemical stimulants, were accepted into the study. Nineteen ( 6 males, 13 females) completed all three stages of the race and 15 runners ( 4 males, 11 females) completed all within- and postrace assessments.

\section{Setting}

The Three Cranes trail run, over 3 days and a total distance of $95 \mathrm{~km}$, was divided into 3 consecutive stages comprising 29.3, 37.9 and 27.8 $\mathrm{km}$, starting and finishing each day at the same base camp. Athletes were accommodated in a race village and full catering was provided for the duration of the race, including at the aid stations along the route. The routes consisted of gravel and forestry roads, narrow rocky mountain footpaths and grassy jeep track. Elevation gains reached 1020,1226 and $680 \mathrm{~m}$, while elevation losses were recorded at 1021 , 1231 and $687 \mathrm{~m}$ during S1 (Stage 1), S2 (Stage 2) and S3 (Stage 3) respectively (Table 1 ). Selected images of the running terrain are presented in Fig. 1.

\section{Baseline measurements}

Following race registration the afternoon before the race, basic anthropometric measurements were recorded, including body mass $(\mathrm{kg})$, stature $(\mathrm{cm})$ in bathing suits without shoes, thigh circumference (TC) (measured $15 \mathrm{~cm}$ above the superior border of the patella) and four-site skinfold (supra-iliac, subscapular, biceps and triceps) for the 
Table 1. Elevation changes ( $m$ ) and ambient temperature ranges during the three stages of the trail run

\begin{tabular}{llll}
\hline & & & $\begin{array}{l}\text { Ambient temp- } \\
\text { Elevation gain Elevation loss } \\
\text { erature range }\left({ }^{\circ} \mathrm{C}\right)\end{array}$ \\
Day 1 & 1020 & 1021 & $11.5-21.7$ \\
Day 2 & 1226 & 1231 & $12.4-22.8$ \\
Day 3 & 680 & 678 & $12.1-21.2$ \\
Total & 2926 & 2930 & \\
\hline
\end{tabular}

determination of $\%$ body fat. ${ }^{12}$ A pre-race questionnaire detailing the athletes' running and racing experience, training terrain and health status was also completed.

\section{Daily protocol}

\section{Pre stage}

The subjects presented themselves to a designated testing area 30 - 90 minutes before the start of the stage, handing in a first earlymorning urine sample. TC was measured, venous blood sampling was conducted in the seated position and resting heart rate (HR) and blood pressure (BP) were recorded after a 3 - 5-minute period of relaxation. A simple pre-stage questionnaire including a rating of the degree of muscle soreness they were experiencing, was completed and the subjects were asked to keep a record of their fluid intake and urine output during the stage. After breakfast and final voiding of bladders, body mass (measured in running attire without shoes), was taken within 5 minutes prior to the start of the event.

\section{Within stage}

Environmental conditions and temperature were supplied on the hour by a meteorological station located $9.5 \mathrm{~km}$ from the base camp. Heart rate was recorded using a polar HR monitor (Polar Electro OY, Finland) at 5-minute intervals and \% age-predicted maximum (APmax) was determined according to the formula, 220-age. ${ }^{14}$

A subsample of 12 athletes volunteered to ingest the Cor-Temp disposable tablets, containing temperature sensors (HQ Inc, Palmetto, FL), at least 3 hours prior to the start of each stage. The HR and intestinal temperature $\left(\mathrm{T}_{\text {intest }}\right)$ data are part of a more detailed study focussing on the relationship between $\mathrm{T}_{\text {intest }}$, $\mathrm{HR}$ and hydration status. ${ }^{13}$

\section{Post stage}

The subjects proceeded directly to the designated testing area where $\mathrm{BP}$, mass and TC were measured within 3 - 5 minutes, blood and urine samples were taken and a short DOMS and post-stage questionnaire providing details regarding the use of non-steroidal anti-inflammatory drugs (NSAIDs) and muscle soreness, were completed. In available athletes $(n=10)$, a further measurement of TC was taken 4 hours after completion of S1 and S2.

The same protocol was followed pre- and post-stage on the 3 days of the race.

\section{Post race}

At 24PR and 72PR, participants presented for further blood/urine sampling, BP, HR and anthropometric measurements. They were also requested to complete a DOMS questionnaire for the 5 days following the race, using a five-point Likert scale, and to return this together with a general post-race questionnaire, following completion of the study.
Haematological analysis and anthropometric measurements Each measurement was carried out by the same researcher for all subjects and at each time point. Venous blood samples were drawn from the antecubital fossa, with subjects in the seated position, within $5-15$ minutes of completing the stage. Blood samples for the assessment of full blood count (FBC) and serum osmolality (sOsm) and urine samples were stored at $4^{\circ} \mathrm{C}$ and transported to a commercial pathology laboratory. Complete blood counts were measured on an Advia-120 Hematology Analyzer (Siemens Healthcare Diagnostics, Deerfield, IL) and included erythrocyte indices and differential leukocyte counts. Both urine and serum osmolality were measured by freezing-point depression, using a Kyoto Daiichi osmostat, OM 6020 (Japan). Urine samples were also assessed for myoglobin $(\mathrm{uMb})$ and specific gravity using the refractive index method on a Beyer Test Strip.

Further aliquots of serum, separated by centrifugation @ $3000 \mathrm{rpm}$ and stored in dry ice were transferred to an $-80^{\circ} \mathrm{C}$ ultrafreezer or transported to a commercial pathology laboratory for analysis of creatine phosphokinase (CPK), cortisol, cardiac troponin $\mathrm{T}(\mathrm{cTnT})$ and high sensitivity $\mathrm{C}$-reactive protein (hsCRP) concentrations.

\section{Statistical analyses}

Data are presented as mean \pm standard deviation (SD). The significance of the accumulative time-dependent stage-induced changes from pre-race $\left(S 1_{\text {pre }}\right)$ to post race $\left(S 1_{\text {post }}, S 2_{\text {pos }} \mathrm{t}, \mathrm{S} 3_{\text {post }}\right)$, as well as recovery rates were assessed comparing $\mathrm{S} 2_{\mathrm{pre}}, \mathrm{S} 3_{\mathrm{pre}}, 24 \mathrm{PR}$ and $72 \mathrm{PR}$ to baseline $\left(S 1_{\text {pre }}\right), S 2_{\text {pre }}$ and $S 3_{\text {pre }}$ were assessed for the entire group using repeated measures one way analysis of variance. The time point of the significant differences was confirmed using a Tukey post hoc analysis.

Comparisons between NSAID users and non-users were conducted using independent Student's $t$-tests. Pearson's product moment coefficient of correlation, with a confidence interval (CI) of $95 \%$, was used to test the relationship between the changes in measured outcomes including CPK, neutrophil concentrations, hsCRP and serum cortisol.

All statistical calculations were performed using SPSS, version 18 (SPSS Inc., Chicago, USA). Level of significance was set at $\mathrm{p}<0.05$.

\section{Results}

Environmental conditions

Temperature recorded on the hour during the three stages of the race ranged from $11.5^{\circ} \mathrm{C}$ to $22.8^{\circ} \mathrm{C}$ (Table 1). It did not rain, maximum wind speed recorded was $2.8 \mathrm{~m} / \mathrm{s}$ and the relative humidity ranged from $54 \%$ to $97 \%$.

\begin{tabular}{ll}
$\begin{array}{l}\text { Table 2. Mean } \pm \text { SD baseline physical characteristics of subjects } \\
(\boldsymbol{n}=19)\end{array}$ \\
\hline Variable & Mean \pm SD \\
Age (years) & $39.3 \pm 7$ \\
Height $(\mathrm{cm})$ & $169.0 \pm 10$ \\
Mass (kg) & $65.8 \pm 12$ \\
\% body fat & $21.7 \pm 4$ \\
Resting heart rate (bpm) & $56.9 \pm 5$ \\
Systolic blood pressure (mmHg) & $124.7 \pm 7$ \\
Diastolic blood pressure $(\mathrm{mmHg})$ & $81.8 \pm 7$
\end{tabular}


Table 3. Training status and performance characteristics of athletes $(n=19)$

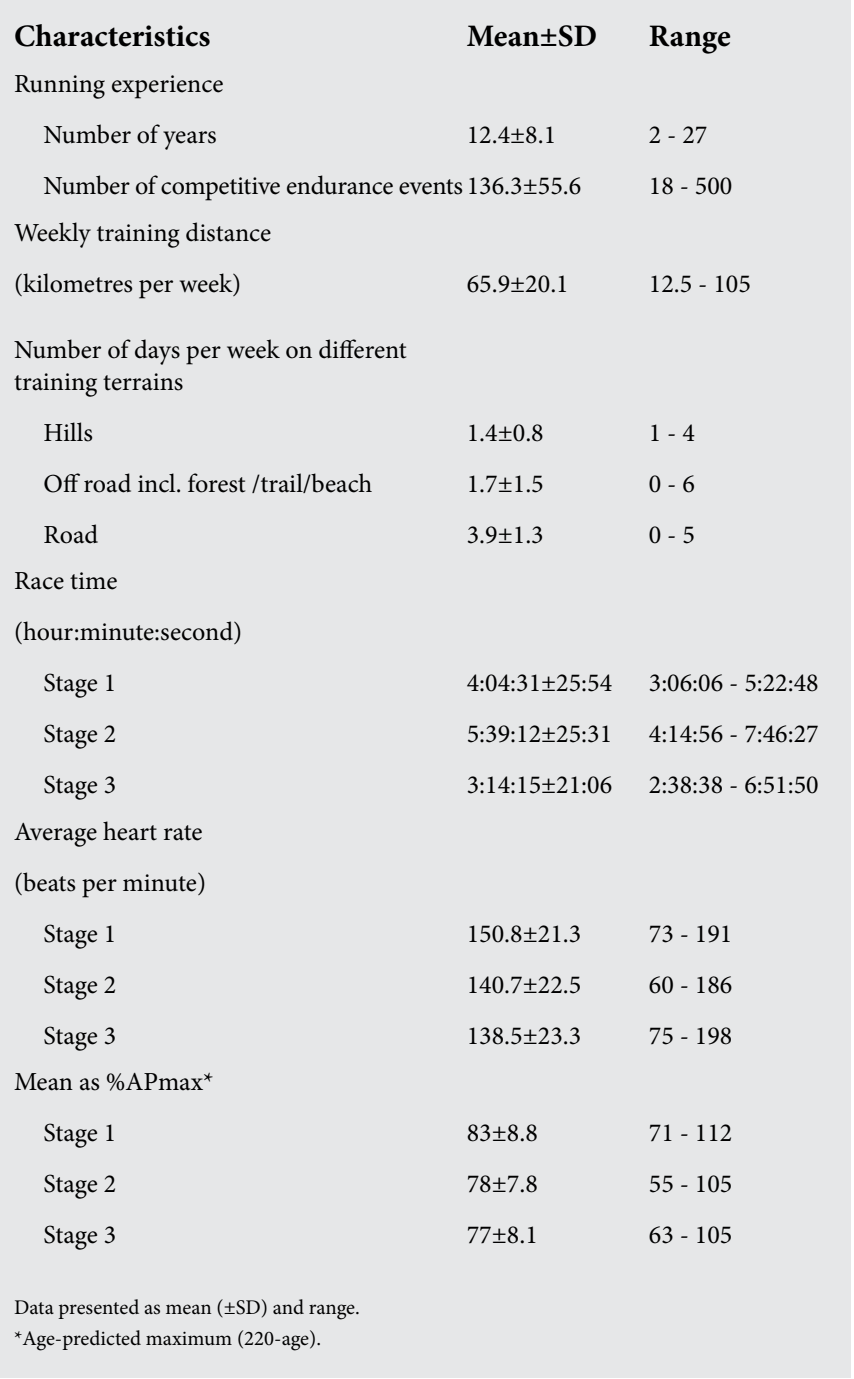

\section{Subjects}

As is shown in Tables 2 and 3, athletes ranged from 25 to 50 years of age, their weekly training distance averaged $65.9 \pm 20.1 \mathrm{~km}$ per week for 12.4 years (range 2 - 27 years) and they presented without abnormalities in their vital signs. Of the 19 subjects, 12 used NSAIDs, including aspirin, ibuprofen and diclofenac.

Of the 21 subjects who initially agreed to participate in the study, one subject (male) withdrew after S1 due to an ankle injury and another (female) after S2 due to medical reasons. The baseline physical characteristics of the remaining 19 subjects are provided in Table 2. Four subjects were however unable to provide blood samples at $24 \mathrm{PR}$ and $72 \mathrm{PR}$.

\section{Intensity of effort}

The mean $\pm \mathrm{SD}$ and range of time spent completing each stage and average HR on the run, are given in Table 3 . Total average running time of the athletes was $12 \mathrm{~h} 57 \pm 2 \mathrm{~h} 51$.

\section{Markers of muscle damage and inflammation}

As shown in Table 4, these included a significant increase in circulating neutrophil concentrations $(\mathrm{p}<0.001)$ which peaked at $10.21 \pm 1.54$
$10^{9} / 1$ at $S 1_{\text {post }}$, serum CPK and hsCRP which peaked at $S 3_{\text {post }}$ at $1488 \pm$ $1053 \mathrm{U} / \mathrm{l}(\mathrm{p} \leq 0.001)$ and $8.91 \pm 6.63 \mathrm{mg} / \mathrm{l}(\mathrm{p} \leq 0.001)$, respectively. cTnT and $\mathrm{uMb}$ were undetected in all samples throughout the 3 -day event.

An exercise-induced increase in serum cortisol concentration was only detected following $\mathrm{S} 2_{\text {post }}$ TC decreased significantly from $54.1 \pm 4.4 \mathrm{~cm}$ at $S 1_{\text {pre }}$ to $51.8 \pm 3.9 \mathrm{~cm}$ at $S 1_{\text {post }}(\mathrm{p}<0.001)$ and returned to the pre-race measurement of $54.1 \pm 4.0 \mathrm{~cm}$ at $24 \mathrm{PR}$. DOMS ranged from $4.8 \pm 1.6,5.6 \pm 1.8$ and $5.1 \pm 1.1$ at $S 1_{\text {post }} \mathrm{S} 2_{\text {post }}$ and $\mathrm{S} 3_{\text {post }}$, respectively, and decreased to $1.73 \pm 1.3$ at $24 \mathrm{PR}$.

Significant positive correlations were evident between blood neutrophil concentrations and serum CPK, $r=0.27,95 \%$ CI [0.11, 0.41 ], serum CPK and hsCRP concentrations, $r=0.50,95 \%$ CI [0.29, $0.66]$ and DOMS and CPK, $\mathrm{r}=0.71,95 \% \mathrm{CI}[0.62,0.78]$.

\section{Dehydration, intestinal temperature $\left(T_{\text {intest }}\right), H R$ and muscle damage}

The mean \% body mass loss for the entire group $(n=19)$ during the three stages was $2.9 \pm 0.7,3.1 \pm 0.8$ and $1.9 \pm 0.9$, while the mean sOsm $(\mathrm{n}=19)$ increased from $288.9 \pm 4.8$ to $293.7 \pm 5.7(\mathrm{p}=0.003), 288.4 \pm 6.4$ to $295.6 \pm 6.0(\mathrm{p}=0.003)$ and $292.2 \pm 4.1$.to $295.0 \pm 5.6(\mathrm{p}=0.006) \mathrm{mOsm} /$ $\mathrm{kg}$, during S1, S2 and S3, respectively. When the pooled data for each stage were compared $(n=51)$, the paired post-pre changes in sOsm correlated inversely with the changes in \% body mass, $r=-0.36,95 \%$ CI [-0.57,-0.094].

The pooled data examining the relationship between the change of sOsm and change in serum CPK for the three stages $(n=57)$ revealed an insignificant positive correlation $(\mathrm{r}=0.034,95 \% \mathrm{CI}[-0.228,0.291]$.

The maximum $\mathrm{T}_{\text {intest }}$ ranged between $38.3^{\circ} \mathrm{C}$ and $40.2^{\circ} \mathrm{C}$ and only exceeded $40^{\circ} \mathrm{C}$ in two of the 12 athletes monitored (Table 5). The relationship between change in $\mathrm{T}_{\text {intest }}$ and serum CPK was insignificant ( $p>0.05$ ) for the 11 individuals from whom complete sets of data were available ( $\mathrm{r}=0.24,95 \% \mathrm{CI}[-0.42,0.734])$.

\section{Users of NSAIDs}

The 12 athletes who used NSAIDs had maximum serum CPK and hsCRP concentrations of $1332 \pm 943.5 \mathrm{U} / \mathrm{l}$ and $8.58 \pm 6.7 \mathrm{mg} / \mathrm{l}$ at $\mathrm{S} 3{ }_{\text {post }}$ and the non-users $1754 \pm 1251.3 \mathrm{U} / \mathrm{l}$ and $9.47 \pm 7.0 \mathrm{mg} / \mathrm{l}$, with no significant difference between the groups $(\mathrm{p}=0.456 ; 0.788)$. The neutrophil count reached a maximum of $9.95 \pm 2.1$ and $9.75 \pm 0.410^{9} / 1$, respectively, for users and non-users $(\mathrm{p}=0.82)$. There was also no significant difference between NSAID users and non-users in terms of serum cortisol, post race DOMS scores, running times, TC or sOsm $(\mathrm{p}>0.05)$.

\section{Discussion}

\section{Evidence of muscle damage and inflammation}

The results of the present study indicate that very little muscle damage and inflammation occurred during 3 days of trail running despite athletes running for a total average of $12 \mathrm{~h} 57$ at an average HR of 77 83\% APmax (Table 3). The serum CPK concentration, which increased progressively to reach peak concentrations at $S 3_{\text {post }}$ indicated only a mild cumulative effect of muscle damage during the race, which rejects the original hypothesis. Furthermore, the changes in neutrophil count, serum cortisol and hsCRP concentrations and DOMS also confirm low levels of inflammation and a rapid recovery. Most athletes in our study had no muscle soreness at 72PR, which correlated with the CPK concentration that had dropped close to the clinical upper limit of normal by $72 \mathrm{PR} .{ }^{15}$ The consistently low release of muscle proteins into the bloodstream in all 19 subjects, which was also not accompanied 
Table 4. Mean \pm SD white and red blood cell indices and markers of muscle damage and inflammatory response before and after every stage and at 24PR and $72 \mathrm{PR}$

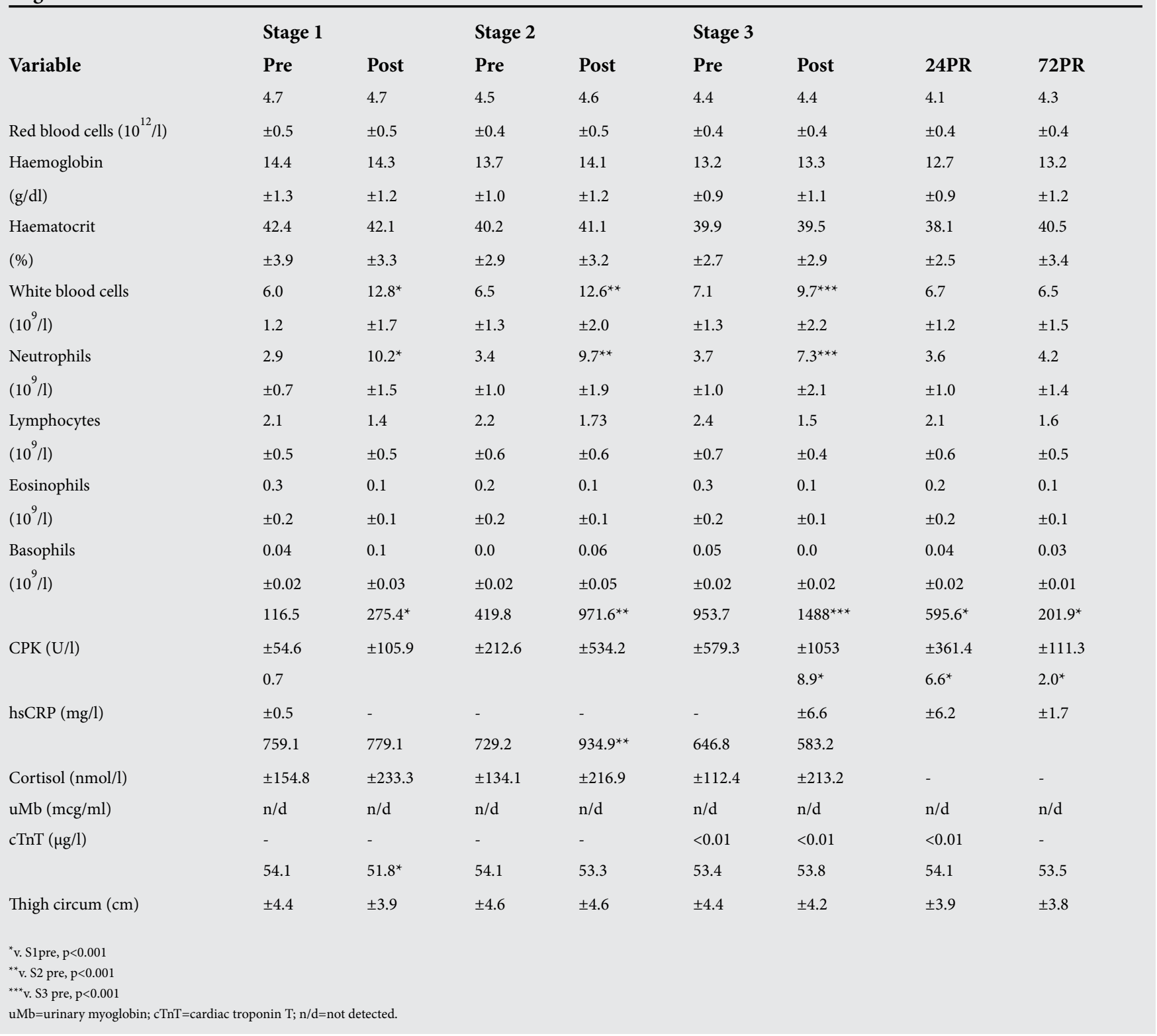

by elevation in cTnT and $\mathrm{uMb}$ in this study, confirms a profile of low degrees of muscle damage. Further evidence is the fact that TC was not significantly elevated at any post-stage or post-race time-point, but was reduced after $\mathrm{S} 1 \quad(\mathrm{p}<0.001)$, confirming previous findings of reduced swelling and a post-race decrease in muscle mass. ${ }^{16}$

The low systemic markers of muscle damage and inflammation, when compared with previous findings following the Comrades Marathon ${ }^{16}$ confirm the findings of Millet et al. ${ }^{1}$ who, in their study on the neuromuscular consequences of extreme running in a $166 \mathrm{~km}$ mountain ultra-marathon, reported that post-race serum concentrations of CPK, hsCRP and neutrophils were lower than those measured after a road race with similar finishing times. ${ }^{1}$ These researchers attributed their findings of low concentrations of systemic markers of muscle damage and inflammation to the relatively soft underfoot surfaces and to the athletes frequently being forced to walk, jump and climb due to the technical demands of the terrain.
During extensive exercise-induced muscle damage myoglobin may be released into the urine and be indicative of exertional rhabdomyolysis and possible risk of renal failure. ${ }^{8}$ Clarkson ${ }^{9}$ however reported that exertional muscle damage in healthy athletes can cause profound serum CPK elevations without renal impairment. In our study the absence of $\mathrm{uMb}$ was confirmed by the relatively low increases in systemic neutrophil, serum CPK and hsCRP concentrations.

In this study we suspect that although the primary factor which reduced the amount of repetitive and eccentric unidirectional stress encountered during the race was most probably the underfoot surfaces, the majority of which were primarily soft, large fluctuations in the pace of running and varied muscle recruitment patterns over the different terrains may also have played a role.

The positive correlation between DOMS scores and CPK concentrations supports the findings of Nieman et al. ${ }^{2}$ who, in their study on 60 participants in the $160 \mathrm{~km} \mathrm{1-day} \mathrm{Western} \mathrm{States}$ Endurance Trail Run in the Sierra Nevada Mountains in northern 
Table 5. Individual $T_{\text {intest }}$, and associated HR, changes in hydration status and peak serum CPK concentration $(n=12)$

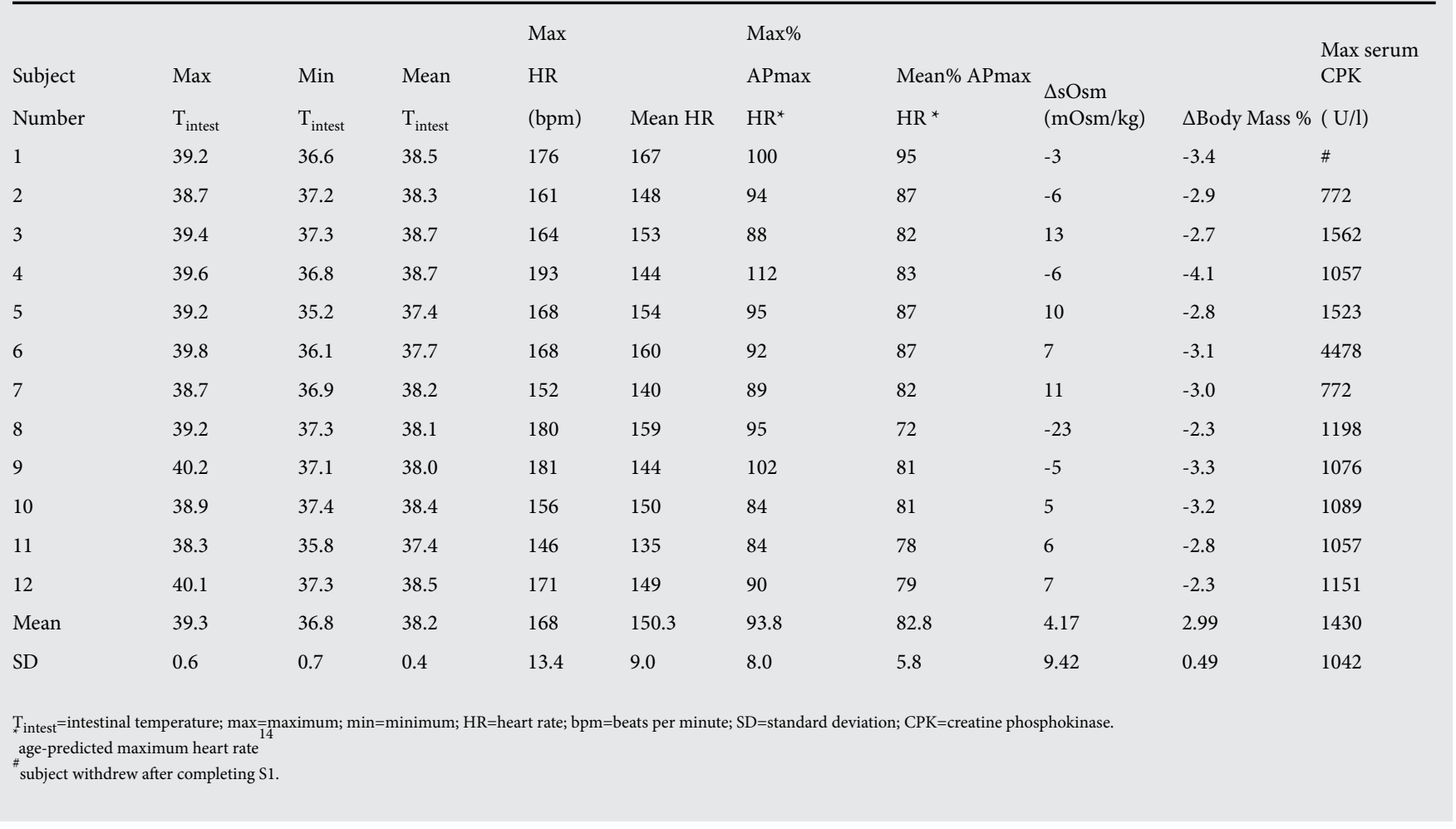

California, showed that there were significant associations between CPK, muscle soreness and the cytokines, interleukin (IL)-6, IL-10, IL-1ra (receptor antagonist), granulocyte colony-stimulating factor and macrophage inflammatory protein $1 \beta$.

\section{Systemic markers of cardiac damage}

The effect of prolonged strenuous exercise on systemic cardiac markers of damage has been studied extensively, ${ }^{18-20}$ with evidence of transient elevations during and immediately after exercise, which return to normal within 3 days in healthy athletes. ${ }^{18,19}$ These temporary elevations have been hypothesised to be due to myocardial stress and reversible cardiomyocyte membrane damage. ${ }^{18,19}$ Exercise is known to cause an increased myocardial oxygen demand and cardiac troponin turnover in all athletes, ${ }^{18}$ which might be linked to tachyarrhythmias and sudden cardiac death, when associated with prolonged increases ( $>3$ days) in cTnT concentrations above $0.05 \mu \mathrm{g} / 1 .{ }^{18}$ At no stage during our study were increased cTnT concentrations measured, supporting the attenuated increase in serum CPK concentration and absent $\mathrm{uMb}$ values as well as the lower concentration of serum cortisol despite maintenance of an intensity of effort which fluctuated from 63 to $112 \%$ APmax. It is possible that serum cTnT also did not increase due to the variation in HR $(60-220 \mathrm{bpm})$ that occurred during this race, which may have stimulated the cardiac muscle at irregular intervals and possibly reduced myocardial stress by permitting periods of recovery.

\section{Users of NSAIDs}

Both NSAID users and non-users were included in this study following recent findings that although markers of muscle inflammation are changed by NSAID usage, degree of muscle damage is unaffected. ${ }^{21,22}$ Nieman et al. ${ }^{2}$ reported that NSAID users did not have reduced race times, muscle damage or DOMS, while Friden and Lieber ${ }^{6}$ reported that administration of NSAIDs after eccentric exercise resulted in a short-term benefit of pain relief, but a long-term detrimental effect on muscle adaptation, inhibiting protein synthesis by suppressing the inflammatory reaction. Paulsen et al. ${ }^{22}$ also indicated that although NSAIDs inhibited prostaglandin synthesis and local and systemic responses, they did not affect actual markers of muscle damage. In this study there was however no statistical difference in the measured markers of muscle damage or inflammatory response between NSAID users and non-users.

Dehydration, intestinal temperature $\left(T_{\text {intest }}\right), H R$ and evidence of muscle damage

Although some athletes in our study experienced up to $4 \%$ body mass loss and others, on occasion, raced at a HR of more than $100 \%$ APmax (Table 5), these athletes did not present with clinical signs of dehydration, severe hyperthermia or increased muscle damage as reflected by changes in sOsm, $\mathrm{T}_{\text {intest }}>40^{\circ} \mathrm{C}$ or changes in serum $\mathrm{CPK}$ concentration, respectively.

As the statistically significant $(\mathrm{p}<0.05)$ inverse correlation between $\%$ change in body mass and post-pre change in sOsm was low $(r=-0.365)$, sOsm, widely reported golden marker of hydration status, ${ }^{23}$ was used to quantitate changes in hydration status.

The correlation between hydration status and systemic markers of muscle damage, as reflected by stage-induced changes in sOsm and serum CPK concentrations, although statistically significant, was low. Hence it cannot be concluded from the 51 sets of paired data reported in this study that hydration status has an overriding effect on systemic markers of muscle damage.

In the 12 individuals in whom continuous recordings of $\mathrm{T}_{\text {intest }}$ were recorded (Table 5), the correlation between race-induced changes in $\mathrm{T}_{\text {intest }}$ and systemic markers of muscle damage was also low and statistically insignificant. The data provided in this study, although 
based on a relatively small sample size, do not provide any support for the suggestion that rises in core body temperature exaxerbate muscle damage.

\section{Conclusion}

The relatively low post-race concentrations of systemic and urinary markers of muscle damage and inflammation, ${ }^{5}$ when compared with those reported following road running events of similar duration, ${ }^{15}$ are attributed to softer underfoot surfaces, large fluctuations in pace of running and varied muscle recruitment patterns over the widely differing terrains. ${ }^{1}$ The sporadic increases in intensity of effort, rises in $\mathrm{T}_{\text {intest }}$, substantial body mass loss and increases in serum osmolality during the event, did not confirm previous suggestions ${ }^{3,4,11}$ that thermal and hydration status is directly related to the degree of muscle damage.

It would be of interest to the investigate the impact of pre-race preparation on markers of muscle damage and inflammatory response found following this multi-day trail running event and to control the nutritional and fluid intake in future field work on multiday trail running.

\section{Acknowledgements}

Special thanks are extended to:

- Ms Heidi Mocke and the Wildlands Conservation Trust for permitting the collection of these data at the 2011 Three Cranes Challenge multiday trail run and for providing the research team with accommodation in the 'race village' located in the Bushwillow Campsite. They are also thanked for provision of the topographical data re the altitude gains and deficits during the race.

- Ergonomics Technologies, Pretoria and the MRC Research Unit for Exercise Science and Sports Medicine for the loan of Cor Temp data recorders which made the continuous monitoring of $\mathrm{HR}$ and $\mathrm{T}_{\text {intest }}$ possible.

- Professor AJ McKune and Mr D Naicker for their support with the field side collection of data reported in this paper.

- Ampath Laboratories for its assistance with phlebotomy and chemical pathology.

- The SA Weather Office for provision of precise data regarding the environmental conditions during the different stages of the race.

- Asokaran Rajh for assistance with graphic artwork.

\section{REFERENCES}

1. Millet GY, Tomazin K, Verges S, et al. Neuromuscular consequences of an extreme mountain ultra-Marathon. PLoS One 2011;6(2):e17059.
2. Nieman DC, Dumke CL, Henson DA, McAnulty SR, Gross SJ, Lind RH. Muscle damage is linked to cytokine changes following a $160-\mathrm{km}$ race. Brain, Behav Immun 2005;19:398-403.

3. Casa DJ, Stearns RL, Lopes RM. Influence of hydration on physiological function and performance during trail running in the heat. J Athl Tr 2010;45:147-156.

4. Stearns RL, Casa DJ, Lopes RM. Influence of hydration status on pacing during trail running in the heat. J Strength Cond Res 2009;23:2533-2541.

5. Clarkson PM, Hubal MJ. Exercise-induced muscle damage in humans. Am J Phys Med Rehab 2002;81(suppl):S52-S69.

6. Friden J, Lieber R. Eccentric exercise-induced injuries to contractile and cytoskeletal muscle fibre components. Acta Physiol Scand 2001;171:321-326.

7. Proske U, Morgan DL. Muscle damage from eccentric exercise mechanism, mechanical signs, adaptation and clinical application. J Physiol 2001;537(2):333-345.

8. Eston RG, Mickleborough J, Baltzopoulos V. Eccentric activation and muscle damage: biomechanical and physiological considerations during downhill running. $\mathrm{Br} \mathrm{J} \mathrm{Sp}$ Med 1995;29(2):89-94

9. Clarkson PM, Kearns AK, Pouzier P, Rubin R, Thompson D. Serum creatine kinase levels and renal function measures in exertional muscle damage. Med Sci Sports Exerc 2006;38(4):623-627.

10. Noakes TD, Myburgh KH, Du Plessis J, et al. Metabolic rate, not percent dehydration, predicts rectal temperature in marathon runners. Med Sci Sports Exerc 1991;23:443449.

11. Cleary MA, Sweeney LA, Kendrick ZV, Sitler MR. Dehydration and symptoms of delayed-onset muscle soreness in hyperthermic males. J Athl Tr 2005;40(4):288-297.

12. Durnin JVGA, Womersley J. Body fat assessed from total body density and its estimation from skinfold thickness: measurements on 481 men and women aged from 16 to 72 years. Br J Nutr 1974;32:77-97.

13. Singh N, Denissen EC, McKune AJ, Peters EM. Intestinal temperature, heart rate and hydration status in multiday trail runners. Cl J Sports Med . 2012. In press.

14. Fox III SM. Naughton, JP, Haskell WL. Physical activity and the prevention of coronary heart disease. Ann Clin Res 1971;3:404-432.

15. Lewis SM, Bain BJ, Bates I. Dacie and Lewis Practical Haematology. 10th ed. USA: Churchill Livingstone, 2006:11-25.

16. Peters EM, Anderson R, Theron AJ. Attenuation of increase in circulating cortisol and enhancement of the acute phase protein response in vitamin C-supplemented ultramarathoners. Int J Sports Med 2000; 120-126.

17. Knechtle B, Kohler G. Running 338 kilometres within five days has no effect on body mass and body fat but reduces skeletal muscle mass - the Isarrun 2006. J Sports Sci Med 2007;6:401-407.

18. Middleton N, George K, Whyte G, Gaze D, Collinson P, Shave R. Cardiac troponin $\mathrm{T}$ release is stimulated by endurance exercise in healthy humans. J Am Coll Cardiol 2008:52(22):1813-1816.

19. Leers MP, Schepers R, Baumgarten R. Effects of a long-distance run on cardiac markers in healthy athletes. Clin Chem Lab Med 2006;44(8):999-1003.

20. La Gerche A, Connelly KA, Mooney DJ, Macisaac AI, Prior DL. Biochemical and fctional abnormalities of left and right ventricular function after ultra-endurance exercise. Heart 2008;94:860-866.

21. Peake J, Nosaka K, Suzuki K. Inflammation and eccentric exercise. Exerc Immunol Rev 2005;11:64-85.

22. Paulsen G, Egner IM, Drange M, et al. A COX-2 inhibitor reduces muscle soreness, but does not influence recovery and adaptation after eccentric exercise. Scand J Med Sci Sports 2010;20(1):e195-207.

23. Armstrong LA, Pumerantz KC, Roti MW, Kavouras SA, Casa DJ, Maresh CM. Human hydration indices. Acute and longitudinal reference values. Int J Sport Nutr Exerc Met 2010;20:145-153. 